\title{
Knowledge, attitude, and practices on intestinal schistosomiasis among primary schoolchildren in the Lake Victoria basin, Rorya District, north-western Tanzania
}

\author{
David Z. Munisi ${ }^{1}{ }^{2 *}$, Joram Buza', Emmanuel A. Mpolya ${ }^{1}$, Teckla Angelo ${ }^{1}$ and Safari M. Kinung'hi ${ }^{3}$
}

\begin{abstract}
Background: Globally school-age children, adolescents and young adults bear the highest burden of schistosomiasis. When developing a specific intervention to improve community's knowledge, attitudes, and practices (KAPs), existing KAPs must be taken into account. Therefore, this study was designed to determine schoolchildren's KAPs on schistosomiasis in the study area.

Methods: A cross-sectional study was conducted in Busanga and Kibuyi villages involving 513 schoolchildren. A pre-tested questionnaire was used to collect socio-demographic data and to assess KAP on schistosomiasis among primary schoolchildren in the study area.

Results: Of the 488 interviewed children, 391 (80.12\%) reported to have heard of schistosomiasis, with the majority $289(73.91 \%)$ citing school as the source of this knowledge. Swimming in the lake, worms, witchcraft, and mosquitoes were mentioned to be the cause for intestinal schistosomiasis. Fishing in the lake, drinking unboiled lake water, walking bare footed, and shaking hands were reported to be practices that may lead to contracting schistosomiasis. Only 156 (39.90\%) of the study respondents reported to know the signs of intestinal schistosomiasis. Avoiding swimming in the lake, drinking unboiled water and eating unwashed fruits were mentioned as preventive measures. Nearly 85\% (412) reported understanding that there was a disease known as schistosomiasis; additionally, 419 (85.86\%) considered schistosomiasis as a dangerous disease and 418 (85.66\%) believed that schistosomiasis was treatable. Fishermen and schoolchildren were reported to be groups most at risk of schistosomiasis infection. Visiting the lake (for swimming and other gatherings) was a common practice among study participants 471 (96.52\%).Nearly 93\% (451) of participants mentioned using lake water for domestic chores, and, although 407 (84.61\%) reported to own a toilet at home, only 229 (55.31\%) reported to always use a toilet for sanitation purposes.

(Continued on next page)
\end{abstract}

\footnotetext{
* Correspondence: munisid@nm-aist.ac.tz; massugii@gmail.com; david.munisi@udom.ac.tz

'Department of Global Health and Bio-Medical Sciences, School of Life Sciences and Bio-Engineering, Nelson Mandela African Institution of Science and Technology, P. O. Box, 447 Arusha, Tanzania

${ }^{2}$ Department of Bio-Medical Sciences, School of Medicine and Dentistry, College of Health Sciences, University of Dodoma, P. O. Box 259, Dodoma, Tanzania

Full list of author information is available at the end of the article
} 
(Continued from previous page)

Conclusion and recommendation: Despite a high rate of awareness among schoolchildren regarding schistosomiasis, there was a persistent gap amongst the children regarding the causes, modes of transmission, symptoms, and preventive measures for the disease. Therefore, an appropriate health education intervention is needed in order to inculcate better knowledge, attitudes, and practices amongst schoolchildren regarding its transmission, control, and prevention as part of a successful schistosomiasis campaign.

Keywords: Schistosomiasis, Knowledge, Attitude, Practices, Schoolchildren, Tanzania

\section{Background}

Schistosomiasis (also known as bilharzias) is a neglected tropical disease (NTD) of public health importance in many tropical and sub-tropical developing countries [1]. The disease occurs in 74 countries worldwide, with an annual estimate of 207 million people being infected globally and an additional 779 million people at risk of infection. Sub-Saharan Africa (SSA) accounts for more than $90 \%$ of the cases $[2,3]$. In Tanzania schistosomiasis is highly prevalent and the country ranks second, after Nigeria, in terms of disease burden on the African continent $[2,4,5]$. Intestinal schistosomiasis caused by Schistosoma mansoni (S. mansoni) is highly endemic in areas surrounding Lake Victoria in Tanzania $[4,6]$, and is implicated in significant morbidity [4, 7]. School-aged children, adolescents, and young adults are groups that bear the highest burden of disease resulting into significant impairment of their physical, nutritional, and cognitive potentials $[3,4,8-10]$.

Three key approaches are currently used to control schistosomiasis, including: improved sanitation, health education, and mass treatment with Praziquantel [11]. However, in many endemic areas including Tanzania, schistosomiasis control has largely relied on periodic mass treatment of school-age children with Praziquantel in accordance with World Health Organization (WHO) recommendations $[8,12]$. Lack of awareness about the modes of transmission of parasitic infections increases the risk of infection and therefore re-infection following treatment [13]. Moreover, in high transmission settings, if there has been no change in the sanitary practices and exposure patterns, re-infection tends to occur within one year following treatment, with such trends being higher among young children and adolescents as their adult counterparts demonstrate an acquired partial resistance to re-infections following treatment $[14,15]$.

When trying to develop specific interventions aiming at improving communities' KAPs, pre-existing capacities must be taken into account [16]. This baseline KAPs level will inform bridging of identified gaps to enhance successful disease control [11]. Health promotion interventions are likely to fail if they are designed without understanding the typical health behaviours of the target population [16]. Furthermore, for interventions focusing on community awareness and involving low socioeconomic communities, it is recommended to create supportive environment for the success and sustainability of other strategies $[17,18]$.

Although schistosomiasis is prevalent in areas surrounding the Victoria Lake Basin in Tanzania, information on the KAPs on the disease of the most at-risk groups is scarce in the public domain. Therefore, this study was designed to determine schoolchildren's KAPs on schistosomiasis in the study area.

\section{Methods \\ Study area}

This study was conducted in Rorya District in northwestern Tanzania. The district is bordered by Tarime District to the east, Butiama District to the south, Lake Victoria to the west, and the Republic of Kenya to the north [19]. For a more detailed description of the study area please see Munisi et al. [20].

\section{Study design}

This study was a cross-sectional baseline survey that assessed knowledge, attitudes, and practices on schistosomiasis among primary schoolchildren in selected schools in the study area.

\section{Study population, inclusion and exclusion criteria}

The study population was comprised of primary schoolchildren aged 6-16 years attending pre-grade one to grade six in Busanga and Kibuyi primary schools in the two villages of Busanga and Kibuyi, respectively. Busanga primary school had a total of 690 pupils, of whom 337 were boys and 353 girls while Kibuyi primary school had 737 pupils of whom, 366 were boys and 371 girls. Schoolchildren aged between 6 and 16 years, who gave assent to participate in the study and whose parents/ guardians provided a written informed consent were eligible for the study. Schoolchildren with a history of being clinically ill and used anti-schistosome drugs within a period of six months before the study, were excluded as described in Munisi et al. [20]. 


\section{Sample size determination and sampling procedures}

This report reflects on a baseline survey nested within a longitudinal interventional study aimed at comparing cure and eggs reduction rates for two different treatment regimens for intestinal schistosomiasis using Praziquantel. Sample size was calculated using a formula for comparing two rates [21]. In the calculations we used cure rates reported from a study of communities living along the shores of Lake Albert in Uganda, which reported cure rates of $41.9 \%$ and $69.1 \%$ for single dose and two doses treatment regimen, respectively [22]. The level of significance was set at $95 \%$ and power of $90 \%$. Adding 30\% annual loss to follow up, a total sample size of 257 per treatment group was required, but we managed to recruit a total of 513 study participants for the entire study.

We conveniently selected two schools within two villages namely Busanga and Kibuyi that lies along the shore of Lake Victoria. We then randomly selected 246 and 267 schoolchildren from Busanga and Kibuyi primary schools, respectively. We sampled children from pre-grade one to grade six. We excluded children in grade seven because they were about to do their final national examinations and they would have been absent during the subsequent follow-up surveys. The number of schoolchildren selected from each class was determined by the probability proportional to the number of children in each class. We attempted to sample equal numbers of boys and girls from each class. Systematic random sampling method was used to obtain study participants for each sex from each class. The schoolchildren in each class were requested to stand in two lines, one for boys and the other one for girls and they were counted. The sampling interval was obtained by dividing the total number of each sex in the class with the number of each sex to be investigated from that class $(\mathrm{N} / \mathrm{n})$. After obtaining a starting point from a table of random numbers, children were sampled according to the sampling interval. The same interval was repeated until the required number of children for each sex in each class was obtained as described in our previous publication [20].

\section{Data collection}

\section{Assessment of socio-demographic information and risk factors}

A pre-tested Swahili translated semi-structured questionnaire was used to gather information on demographic characteristics of the study participants and their KAPs towards S. mansoni infection. Variables such as age, sex, socio-economic activities of parents/guardians, sanitary practices, water contact behaviour and history of receiving anti-schistosomal treatment were assessed. Also, the questionnaire involved questions concerning the knowledge about schistosomiasis aetiology, transmission, clinical manifestations, prevention, and control. The questionnaire was initially developed in English, then translated to Swahili, and then back-translated by a different person who was blinded to the original questionnaire.

\section{Data analysis}

The collected data were entered into a database using EpiData Version 3.1. Data analysis was done using STATA Version 12.1 (Stata Corp, Texas, USA). Descriptive statistics, including percentages and mean values, were used to summarize the data. The chi-square test was used to assess the association between categorical variables. $P$-values less than 0.05 were considered statistically significant.

\section{Ethical statement}

The Medical Research Coordination Committee (MRCC) of the National Institute for Medical Research (NIMR), Tanzania provided an approval for this study (Reference number NIMR/HQ/R.8a/Vol. IX/1990). The study received further approval from the District Executive Director, District Education Officer, and Medical Officer of Rorya District Council. Prior to the study, the research team conducted meetings with the village executive officers, teachers, and students of selected villages and schools, respectively. During these meetings, the objectives of the study, the study procedures, sampling, study benefits, and potential risks and discomforts were explained. Informed consent for all children who participated in the study was sought from parents or legal guardians through an informed consent form. Assent was sought from children who were also informed of their rights to refuse to participate in the study and to withdraw from the study at any time. At baseline, all children were given a standard dose of praziquantel $(40 \mathrm{mg} / \mathrm{kg})$ and albendazole $(400 \mathrm{mg})$ as a single dose after stool sample collection. Treatment with praziquantel was given after a meal which was prepared and offered at school to minimize potential side effects. Treatment was performed under direct observation (DOT) of a qualified nurse.

\section{Results \\ Socio-demographic characteristics of the study participants}

A total of 513 schoolchildren from the two primary schools were enrolled in the study. Out of these, 488 (95.13\%) completed the interview. Of the interviewed children 238 (48.77\%) were from Busanga village and 250 (51.23\%) were from Kibuyi village. Among the study participants, 244 (50.00\%) were males and the other 244 $(50.00 \%)$ were females. The numbers of boys and girls in Busanga primary school were 117 (49.16\%) and 121 
(50.84\%), respectively whereas the numbers of boys and girls in Kibuyi primary school were $127(50.80 \%)$ and 123 (49.20\%), respectively. The age of participating schoolchildren ranged from 6 to 16 years with a mean age of $10.97 \pm 2.36$ years. The distribution of children with 6-9 years were $136(27.87 \%), 10-12$ years were 208 (42.62\%) and $13-16$ years were $144(29.51 \%)$.

\section{Respondent's knowledge on the cause, transmission, symptoms and preventive measures against Schistosomiasis}

Of the 488 interviewed children, 391 (80.12\%) reported hearing of schistosomiasis, with the majority (289, $73.91 \%$ ) of the children mentioning school as a source of information regarding schistosomiasis. The majority 339, $(86.70 \%)$ of the children mentioned swimming in the lake to be the cause of schistosomiasis, while only 44 $(11.25 \%)$ mentioned that worms cause the disease. Witchcraft was mentioned by $15(3.84 \%)$ of those who reported to have heard about the disease, while 13 (3.32\%) mentioned mosquito to be responsible for causing intestinal schistosomiasis (Table 1). Respecting contributory activities for schistosomiasis infection, the majority of the respondents $(339,86.7 \%)$ mentioned swimming in the lake and fishing $(316,80.86 \%)$. Fewer respondents indicated causes such as drinking unboiled water (251, 64.19\%); walking barefooted (220;56.27\%) and shaking hands $(49,12.53 \%)$ respectively. In terms of knowledge of symptoms for intestinal schistosomiasis, only $156(39.9 \%)$ of the study respondents reported knowing the symptoms for intestinal schistosomiasis, of which $136(87.18 \%)$ mentioned stomach ache. The majority of respondents $(306,78.26 \%)$ mentioned avoiding swimming in the lake as a preventive measure for intestinal schistosomiasis, Avoiding drinking unboiled water and washing fruits before eating were also mentioned by more than half the respondents [232 (59.34\%); 251 (64.19\%)], respectively (Table 1 ).

\section{Attitude, risk perception and practices of the study participants towards schistosomiasis}

The majority of the children [412 (84.77\%)] understood that there was schistosomiasis in their village of residence. Among the interviewed children, 419 (85.86\%) considered schistosomiasis to be a dangerous disease,while 418 (85.66\%) understood that the disease can be treated (Table 2). The majority of respondents [354, 81.76\%] reported that fishermen were the most at-risk group for intestinal schistosomiasis, schoolchildren were also mentioned to be among the at-risk group by 325 ( $75.06 \%)$ participants (Table 2). The most common source of water used for domestic chores was Lake Victoria water, with $451(92.42 \%)$ of study participants reporting this source (Table 2). Toilet ownership was common with 407
Table 1 Respondents' knowledge on the cause, transmission, symptoms and preventive measures for Schistosomiasis

\begin{tabular}{|c|c|c|}
\hline Variable & Frequency & Percentage \\
\hline Ever heard of Schistosomiasis $(n=488)$ & 391 & 80.12 \\
\hline \multicolumn{3}{|l|}{ Source of information $(n=391)$} \\
\hline School & 289 & 73.91 \\
\hline Home & 149 & 38.11 \\
\hline Local dispensary & 53 & 13.55 \\
\hline News media & 93 & 23.79 \\
\hline \multicolumn{3}{|l|}{ Causes of Schistosomiasis $(n=391)$} \\
\hline Schistosomiasis is caused by worms & 44 & 11.25 \\
\hline Schistosomiasis is caused by mosquitoes & 13 & 3.32 \\
\hline Schistosomiasis is caused by witchcraft & 15 & 3.84 \\
\hline $\begin{array}{l}\text { Schistosomiasis is caused by swimming } \\
\text { in ponds }\end{array}$ & 102 & 26.09 \\
\hline $\begin{array}{l}\text { Schistosomiasis is caused by swimming } \\
\text { in river }\end{array}$ & 49 & 12.53 \\
\hline $\begin{array}{l}\text { Schistosomiasis is caused by swimming } \\
\text { in lake }\end{array}$ & 339 & 86.70 \\
\hline I don't know what causes Schistosomiasis & 37 & 9.46 \\
\hline \multicolumn{3}{|l|}{ Transmission of intestinal schistosomiasis } \\
\hline \multicolumn{3}{|c|}{ Activities that may lead to getting Intestinal schistosomiasis $(n=391)$} \\
\hline Swimming in the lake & 339 & 86.70 \\
\hline Fishing in the lake & 316 & 80.82 \\
\hline Washing clothes in the lake & 251 & 64.19 \\
\hline Washing dishes in the lake & 220 & 56.27 \\
\hline Drinking unboiled water & 267 & 67.77 \\
\hline Walking barefooted & 188 & 48.08 \\
\hline Shaking hands & 49 & 12.53 \\
\hline \multicolumn{3}{|l|}{ Signs for intestinal schistosomiasis $(n=156)$} \\
\hline $\begin{array}{l}\text { Know the signs for intestinal } \\
\text { schistosomiasis }\end{array}$ & 156 & 39.90 \\
\hline Blood in urine (Haematuria) & 81 & 51.92 \\
\hline Painful urination & 40 & 25.64 \\
\hline Stomach ache & 136 & 87.18 \\
\hline Swelling abdomen & 61 & 39.10 \\
\hline \multicolumn{3}{|c|}{ Preventive measures for intestinal schistosomiasis $(n=391)$} \\
\hline Avoiding swimming in the lake & 306 & 78.26 \\
\hline $\begin{array}{l}\text { Wearing gum boots when in contact } \\
\text { with lake water }\end{array}$ & 258 & 65.98 \\
\hline Always using toilets & 289 & 73.91 \\
\hline Avoiding touching the soil & 117 & 29.92 \\
\hline Washing hands & 169 & 43.22 \\
\hline Avoiding drinking unboiled water & 232 & 59.34 \\
\hline Washing fruits before eating & 251 & 64.19 \\
\hline
\end{tabular}

(84.61\%) reporting a toilet at home with the main toilet type being a pit latrine [299, 62.16\%]. There were significantly more children who reported not to have a toilet at 
Table 2 Attitude, risk perception and practices of the study participants towards schistosomiasis

\begin{tabular}{|c|c|c|}
\hline Variable & Frequency & $\begin{array}{l}\text { Percentage } \\
(1 \%)\end{array}$ \\
\hline \multicolumn{3}{|l|}{ Source of water used at home $(n=488)$} \\
\hline Tap water & 39 & 7.99 \\
\hline Lake water & 451 & 92.42 \\
\hline Bore hole & 15 & 3.07 \\
\hline Open well & 51 & 10.45 \\
\hline River water & 16 & 3.28 \\
\hline \multicolumn{3}{|l|}{ Type of toilet at home $(n=481)$} \\
\hline Pour flush toilet & 108 & 22.45 \\
\hline Pit latrine & 299 & 62.16 \\
\hline No toilet & 74 & 15.38 \\
\hline \multicolumn{3}{|l|}{ Sanitary practices } \\
\hline Always use toilet $(n=414)$ & 229 & 55.31 \\
\hline Use toilet only sometimes $(n=414)$ & 185 & 44.69 \\
\hline $\begin{array}{l}\text { Sometimes defecate along the } \\
\text { lake shore }(n=183)\end{array}$ & 154 & 84.15 \\
\hline $\begin{array}{l}\text { Sometimes defecate in the bushes } \\
(n=183)\end{array}$ & 181 & 98.91 \\
\hline \multicolumn{3}{|l|}{ Water contact habits ( $n=488$ ) } \\
\hline Visiting the lake & 471 & 96.52 \\
\hline \multicolumn{3}{|l|}{ Frequency of visiting the lake (469) } \\
\hline Once a month & 11 & 2.35 \\
\hline 2-3 times a week & 46 & 9.81 \\
\hline Everyday & 412 & 87.85 \\
\hline \multicolumn{3}{|l|}{ Risk perception $(n=488)$} \\
\hline Schistosomiasis can be treated & 418 & 85.66 \\
\hline There is schistosomiasis where I am living & 412 & 84.77 \\
\hline Schistosomiasis is a dangerous disease & 419 & 85.86 \\
\hline Schistosomiasis is a chronic disease & 40 & 8.20 \\
\hline Schistosomiasis is a shameful disease & 4 & 0.82 \\
\hline $\begin{array}{l}\text { Schistosomiasis is not a very dangerous } \\
\text { disease }\end{array}$ & 21 & 4.30 \\
\hline I don't know & 4 & 0.82 \\
\hline \multicolumn{3}{|l|}{ Most at risk groups ( $n=433)$} \\
\hline School children & 325 & 75.06 \\
\hline Women & 58 & 13.39 \\
\hline Rice farmers & 32 & 7.39 \\
\hline Fishermen & 354 & 81.76 \\
\hline
\end{tabular}

home in Busanga (25.32\%) than Kibuyi (6.048\%) (Fig. 1) $(p<0.001)$. However, only $229(55.31 \%)$ reported to always use a toilet, while 185 (44.69\%) reported to use a toilet only sometimes. Defecating in the bushes was reported by 184 (98.91\%) of those who use the toilets only sometimes and 154 (84.15\%) reported to also defecate along the lakeshore. Visiting Lake Victoria was a common practice among study participants (471,96.52\%) of which $412(87.85 \%)$ reported daily visits (Table 2$)$. Slightly more than half $(50.84 \%)$ of the respondents in Busanga village reported using a toilet sometimes, while it was only $40 \%$ in Kibuyi village yielding a statistically significant ( $p=0.028)$ finding (Fig. 2).

\section{Discussion}

The success of schistosomiasis control interventions in endemic areas can be realized if children, who are the targets of the currently used control interventions, have adequate knowledge, positive attitudes, and correct preventive and control practices. This study aimed at exploring the level of KAPs of schoolchildren on schistosomiasis to inform the development of a targeted control strategy against schistosomiasis.

Our findings showed that majority of the respondents understood that there was schistosomiasis in their village of residence and considered schistosomiasis as a dangerous disease. A similar finding was also reported in other studies elsewhere [11, 13]. The majority also admitted that the disease could be treated, as it was also reported by Mazigo et al. [23].

In this study, it was found that majority of respondents had heard about intestinal schistosomiasis, which is similar to previous study findings [11, 13, 23, 24]. However, just having heard about the disease is insufficient, with a proper understanding of the disease and its causes and mode of transmission required [16]. About three quarters of respondents reported the school to be one of the major sources of information about schistosomiasis, again reflected in previous studies and making schools a potential strategic channel for communicating health information to this most susceptible age group $[23,25,26]$. In contrast, other studies reported the most common source of information about schistosomiasis to be family or neighbours, which may dilute the knowledge leading to various misconceptions [13].

Although the majority of the study participants mentioned swimming in the lake to be one way by which intestinal schistosomiasis could be transmitted, visiting the lake was common in this community. This high rate of visiting the lake was also reported in another study where $84 \%$ of the children reported going to the lake [23]. Children also mentioned fishing as an activity through which schistosomiasis might be transmitted. This high level of knowledge on schistosomiasis transmission could be due to the endemic rate in this community. Of greater concern is how this high rate of knowledge has not concomitantly translated into preventive practices [20]. Surprisingly, only a few (11.25\%) of the participants knew that the cause of schistosomiasis were worms, which seems to be a common issue reported in other studies [23, 24, 26]. Misconceptions about the true 


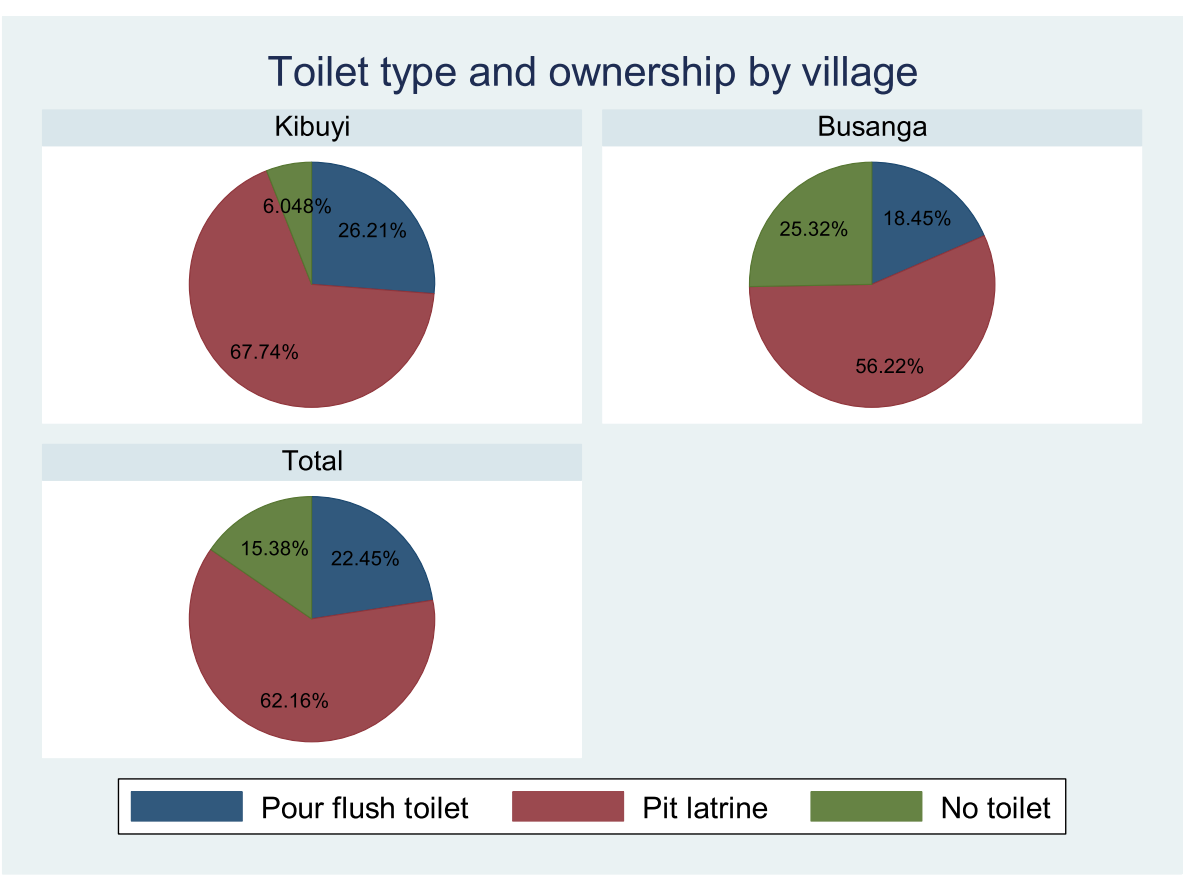

Fig. 1 Toilet type and ownership by village of residence

cause of schistosomiasis were also present amongst interviewed schoolchildren who believed witchcraft and mosquitoes were causes of intestinal schistosomiasis. Such misconceptions may be a hindrance to implementation of a successful control program; therefore they need to be clarified before launching an integrated control program in the area. Similar to previous studies [11, 27], misconceptions about the true mode of transmission were held by many children in these communities, with beliefs that schistosomiasis could be transmitted by drinking unboiled water; walking barefoot, and shaking hands. As many inhabitants of these areas use lake water for domestic

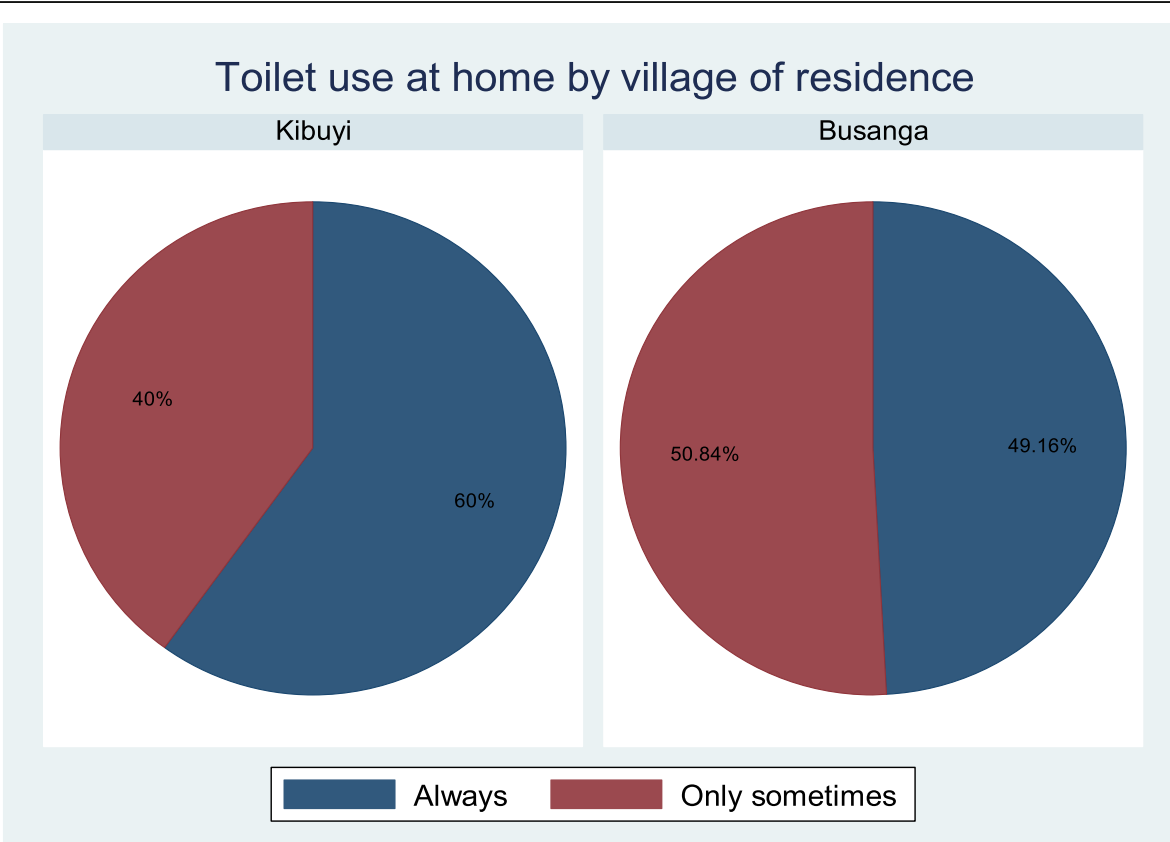

Fig. 2 Toilet use at home by village of residence 
purpose including drinking and they do suffer recurrent acute water-borne infections, which may have prompted them to believe that intestinal schistosomiasis could be transmitted by drinking unboiled lake water [27].

Despite high rates of having heard about schistosomiasis, only $39.9 \%$ of the respondents reported knowing the symptoms of schistosomiasis. Low level of awareness on the signs and symptoms for intestinal schistosomiasis were reported in Siphofaneni area in the Lowvelds of Swaziland [24]. In this current study, the majority mentioned stomach ache to be a symptom for intestinal schistosomiasis contrary to blood in stool which was the most commonly reported symptom associated with intestinal schistosomiasis in western Côte d'Ivoire [26].

Despite the majority of the respondents knowing that avoiding swimming in lake water may be preventive for schistosomiasis, visiting the lake was a common practice amongst study participants due to dependency on the water for domestic and economic use including fishing, swimming, washing utensils, drinking, cooking, and watering animals. Similar results were also reported in western Kenya [11]. Misconceptions on proper preventive practices against intestinal schistosomiasis were common among study participants, including avoiding drinking unboiled lake water and washing fruits before eating. This was a misconception likely rooted in such preventive measures applying to other water-borne infections which are also endemic in the area. The observed knowledge gap on the signs, symptoms, and preventive measures against intestinal schistosomiasis among study respondents indicates lack of appropriate health education targeting this at-risk group which should be provided in combination with mass treatment campaigns. Such campaigns should enhance children's knowledge and therefore influence positive practices which will lower re-infection rates following mass drug administration campaigns.

Respondents in this study consider fishermen and schoolchildren to be the most at risk groups for schistosomiasis. These two groups were also perceived to be the most at risk groups in a different study [11]. Despite high knowledge on the mode of transmission of intestinal schistosomiasis and the reported high rate of toilet ownership, indiscriminate defecation practices were common among study participants. This practice implies that the knowledge on the mode of transmission for intestinal schistosomiasis has not influenced children's sanitation (toileting) practices. This finding may signify that behavioural changes, which are often more difficult to achieve, are not guaranteed by awareness alone, and that long intervals are required to ensure uptake and compliance of healthier practices $[13,28]$. Similar findings have been reported elsewhere, children felt comfortable defecating close to lake water when at the lake, as it appeared inconvenient to go back home just to answer a call of nature while there was water around to clean themselves thereafter [11, 13, 23]. In another study participants reported that, in some cases where the toilets were present, people still preferred defecating in the bush where they found to be more comfortable as compared to pit latrines that were feared to house snakes and were often full [11]. These findings suggests that provision of toilets alone is not enough to eliminate the indiscriminate defecation practices, providing public education on the importance of properly using toilets in the control of schistosomiasis and other parasitic infections needs to be emphasized in a manner which reaches the targeted populations [13].

The study further revealed that toilet ownership was lower in Busanga than Kibuyi village and more respondents reported to have indiscriminate defecation practice in Busanga than was reported in Kibuyi village. This observation is likely related to the proximity of Kibuyi village to Musoma municipality which is the headquarters for Mara region potentially leading to people having better access to health information than people at Busanga village which is more distal from the larger centre. Location of the household has been found to be a significant factor in the access and utilization of toilets [29].

\section{Conclusion and recommendation}

This study found that most schoolchildren in two villages of Rorya districts were familiar to schistosomiasis with majority mentioning schools to be the source of schistosomiasis knowledge. Despite this high rate of awareness about schistosomiasis many children had misconceptions about the true cause, mode of transmission, symptoms, and preventive measures for intestinal schistosomiasis. Thus, an appropriate health education intervention and community mobilisation are recommended in order to enhance schistosomiasis prevention and inculcate a better knowledge onto schoolchildren regarding its transmission and prevention. For an effective and successful control program against schistosomiasis, there is a need for provision of proper health education to the most at-risk groups who serve both as the main source of infection and victims for the high disease burden.

\section{Abbreviations}

NIMR: National Institute for Medical Research; NTD: Neglected Tropical Diseases

\section{Acknowledgements}

The authors thank the District Executive Director, District Medical Officer, and District Education Officer for Rorya District for granting permission to undertake this study. They also thank the head teachers, teachers, and pupils in each of the schools that participated in this study and all the research team members for their assistance in the field work. 


\section{Funding}

This study received financial support from the Government of Tanzania through the Nelson Mandela African Institution of Science and Technology and formed part of the PhD training programme for DZM.

\section{Availability of data and materials}

The datasets used and/or analysed during the current study available from the corresponding author on reasonable request.

\section{Authors' contributions}

The study was designed by DZM and SMK. Data collection was done by DZM and SMK. DZM, SMK, and EAM participated in data analysis and manuscript preparation. TA, SMK, JB, and EAM critically reviewed the manuscript and the interpretation of the results. All authors read and approved the final manuscript.

\section{Ethics approval and consent to participate}

The Medical Research Coordination Committee (MRCC) of the National Institute for Medical Research (NIMR), Tanzania offered an approval for this study (Reference number NIMR/HQ/R.8a/Nol. IX/1990). The study received further approval from the District Executive Director, District Education Officer, and Medical Officer of Rorya District Council. Prior to the commencement of the study, the research team conducted meetings with the village executive officers, teachers, and students of selected villages and schools, respectively. During these meetings, the objectives of the study, the study procedures to be followed, samples to be taken, study benefits, and potential risks and discomforts were explained. Informed consent for all children who participated in the study was sought from parents and legal guardians by signing an informed consent form. Assent was sought from children who were also informed of their rights to refuse to participate in the study and to withdraw from the study at any time. At baseline, all children were given a standard dose of praziquantel $(40 \mathrm{mg} / \mathrm{kg})$ and albendazole (400 mg) as a single dose after stool sample collection. Treatment with praziquantel was given after a meal which was prepared and offered at school to minimize potential side effects. Treatment was performed under direct observation (DOT) of a qualified nurse.

\section{Consent for publication}

Not applicable.

\section{Competing interests}

The authors declare that they have no competing interests.

\section{Publisher's Note}

Springer Nature remains neutral with regard to jurisdictional claims in published maps and institutional affiliations.

\section{Author details}

${ }^{1}$ Department of Global Health and Bio-Medical Sciences, School of Life Sciences and Bio-Engineering, Nelson Mandela African Institution of Science and Technology, P. O. Box, 447 Arusha, Tanzania. ${ }^{2}$ Department of Bio-Medical Sciences, School of Medicine and Dentistry, College of Health Sciences, University of Dodoma, P. O. Box 259, Dodoma, Tanzania. ${ }^{3}$ National Institute for Medical Research (NIMR), Mwanza Research Centre, Isamilo Road, P. O. Box 1462, Mwanza, Tanzania.

Received: 30 December 2016 Accepted: 18 September 2017 Published online: 21 September 2017

\section{References}

1. Bruun B, Aagaard-Hansen J (2008) The social context of schistosomiasis and its control: an introduction and annotated bibliography: World Health Organization.

2. Steinmann P, Keiser J, Bos R, Tanner M, Utzinger J. Schistosomiasis and water resources development: systematic review, meta-analysis, and estimates of people at risk. Lancet Infect Dis. 2006;6:411-25.

3. Crompton D. How much human helminthiasis is there in the world? J Parasitol. 1999:397-403.

4. Mazigo HD, Nuwaha F, Kinung'hi SM, Morona D, de Moira AP, et al. (2012) Epidemiology and control of human schistosomiasis in Tanzania. Parasit Vectors 5: 274-274.
5. Ross AGPBPB, Sleigh AC, Olds GR, Li Y, Williams GM, McManus DP. Schistosomiasis. N Engl J Med. 2002;346:1212-20.

6. Lwambo NJ, Siza JE, Brooker S, Bundy DA, Guyatt H. Patterns of concurrent hookworm infection and schistosomiasis in schoolchildren in Tanzania. Trans R Soc Trop Med Hyg. 1999;93:497-502.

7. Malenganisho WL, Magnussen P, Friis H, Siza J, Kaatano G, et al. Schistosoma mansoni morbidity among adults in two villages along Lake Victoria shores in Mwanza District, Tanzania. Trans R Soc Trop Med Hyg. 2008;102:532-41.

8. Montresor A, Crompton DWT, Gyorkos TW, Savioli L (2002) Helminth control in school-age children: a guide for managers of control programmes: World Health Organization.

9. Hotez PJ, Kamath A. Neglected tropical diseases in sub-saharan Africa: review of their prevalence, distribution, and disease burden. PLoS Negl Trop Dis. 2009;3:e412.

10. WHO (2002) Prevention and control of schistosomiasis and soiltransmittedhelminthiasis: report of a WHO expert committee. 1-57 p.

11. Odhiambo GO, Musuva RM, Atuncha VO, Mutete ET, Odiere MR, et al. Low levels of awareness despite high prevalence of schistosomiasis among communities in Nyalenda informal settlement, Kisumu City, Western Kenya. PLoS Negl Trop Dis. 2014;8:e2784

12. Colley DG, Bustinduy AL, Secor WE, King CH. Human schistosomiasis. Lancet. 2014:383:2253-64.

13. Dawaki S, Al-Mekhlafi HM, Ithoi I, Ibrahim J, Abdulsalam AM, et al. The Menace of Schistosomiasis in Nigeria: Knowledge, Attitude, and Practices Regarding Schistosomiasis among Rural Communities in Kano State. PLOS One. 2015:10:e0143667.

14. Tukahebwa EM, Vennervald BJ, Nuwaha F, Kabatereine NB, Magnussen P. Comparative efficacy of one versus two doses of praziquantel on cure rate of Schistosoma mansoni infection and re-infection in Mayuge District, Uganda. Transactions of The Royal Society of Tropical Medicine and Hygiene: trt024. 2013;107:397-404.

15. Kabatereine N, Vennervald B, Ouma J, Kemijumbi J, Butterworth A, et al. Adult resistance to schistosomiasis mansoni: age-dependence of reinfection remains constant in communities with diverse exposure patterns. Parasitology. 1999:118:101-5.

16. Musuva RM, Awiti A, Omedo M, Ogutu M, Secor WE, et al. Community knowledge, attitudes and practices on schistosomiasis in western Kenya-the SCORE Project. Am J Trop Med Hyg. 2014;90:646-52.

17. Joshi A, Banjara MR. Malaria related knowledge, practices and behaviour of people in Nepal. J Vector Borne Dis. 2008;45:44.

18. Govere J, Durrheim D, la Grange K, Mabuza A, Booman M. Community knowledge and perceptions about malaria and practices influencing malaria control in Mpumalanga Province, South Africa. South African medical journal= Suid-Afrikaanse tydskrif vir geneeskunde. 2000;90:611-6.

19. Webber GC, Chirangi B. Women's Health in Women's Hands: A Pilot Study Assessing the Feasibility of Providing Women With Medications to Reduce Postpartum Hemorrhage and Sepsis in Rural Tanzania. Health Care Women Int. 2014;35:758-70.

20. Munisi DZ, Buza J, Mpolya EA, Kinung'hi SM. Intestinal Schistosomiasis among Primary Schoolchildren in Two On-Shore Communities in Rorya District, Northwestern Tanzania: Prevalence, Intensity of Infection and Associated Risk Factors. J Parasitol Res. 2016;2016:1859737.

21. Hardon A, Boonmongkon P, Streefland $P$, Tan ML, Hongvivatana $T$, Geest S, Staa A, Varkevisser C. Applied Health Research Manual Anthropology of Health and Health Care. CIP-Data Konkinklijke Bibliotheek: Den Haag; 1994.

22. Kabatereine N, Kemijumbi J, Ouma J, Sturrock R, Butterworth A, et al. Efficacy and side effects of praziquantel treatment in a highly endemic Schistosoma mansoni focus at Lake Albert, Uganda. Trans R Soc Trop Med Hyg. 2003;97:599-603

23. Mazigo HD, Waihenya R, Mkoji GM, Zinga M, Ambrose EE, et al. Intestinal schistosomiasis: prevalence, knowledge, attitude and practices among school children in an endemic area of north western Tanzania. J Rural Trop Public Health. 2010;9:53-60.

24. Maseko TS, Mkhonta N, Masuku SK, Dlamini SV, Fan C-K. Schistosomiasis knowledge, attitude, practices and associated factors among primary school children in Siphofaneni area in the Lowveld of Swaziland. Immunology and Infection: Journal of Microbiology; 2016. 
25. Midzi N, Mtapuri-Zinyowera S, Mapingure MP, Paul NH, Sangweme D, et al. Knowledge attitudes and practices of grade three primary schoolchildren in relation to schistosomiasis, soil transmitted helminthiasis and malaria in Zimbabwe. BMC Infect Dis. 2011:11:1.

26. Acka CA, Raso G, N'Goran EK, Tschannen AB, Bogoch II, et al. Parasitic worms: knowledge, attitudes, and practices in western Côte d'lvoire with implications for integrated control. PLoS Negl Trop Dis. 2010;4:e910.

27. Xinhua MGARa (2016) Africa's largest fresh water lake said to be major waterborne disease breeding site. Lake Victoria contaminated by raw sewage, putting millions of people at risk: M\&G Africa.

28. Asaolu S, Ofoezie I. The role of health education and sanitation in the control of helminth infections. Acta Trop. 2003;86:283-94.

29. Mahama A (2013) Determinants of Factors Influencing Householders' Access to Improved Water and Sanitation Facilities in Selected Low-Income Urban Areas of Accra: University of Ghana.

Submit your next manuscript to BioMed Central and we will help you at every step:

- We accept pre-submission inquiries

- Our selector tool helps you to find the most relevant journal

- We provide round the clock customer support

- Convenient online submission

- Thorough peer review

- Inclusion in PubMed and all major indexing services

- Maximum visibility for your research

Submit your manuscript at www.biomedcentral.com/submit
Biomed Central 